\title{
Additions to the taxonomy of the Afrotropical Tetramorium weitzeckeri species complex (Hymenoptera, Formicidae, Myrmicinae), with the description of a new species from Kenya
}

\author{
Francisco HITA GARCIA ${ }^{1,3, *}$ \& Georg FISCHER ${ }^{2,4}$ \\ ${ }^{1}$ Entomology, California Academy of Sciences, 55 Music Concourse Drive, San Francisco, \\ CA 94118, U.S.A. \\ * Corresponding author: fhitagarcia@gmail.com \\ ${ }^{2}$ Entomology, California Academy of Sciences, 55 Music Concourse Drive, San Francisco, \\ CA 94118, U.S.A. \\ Email: georgf81@gmail.com \\ ${ }^{3}$ urn:1sid:zoobank.org:author:B7ADF56F-935D-4BD8-ADB3-50E96F8BB463 \\ ${ }^{4}$ urn:1sid:zoobank.org:author:16CEBC67-ECE7-4FC4-B537-085F0E26E85A
}

\begin{abstract}
This study presents a taxonomic update of the Tetramorium weitzeckeri species group. Tetramorium mpala sp. nov. is described from Laikipia, Kenya, and placed in the T. weitzeckeri species complex. In addition, we also provide an illustrated identification key to the three species complexes of the T. weitzeckeri species group, and an updated illustrated identification key to the species of the T. weitzeckeri species complex.
\end{abstract}

Keywords. Kenya, Laikipia, Mpala Research Centre, taxonomy, Tetramoriini

Hita Garcia F. \& Fischer G. 2014. Additions to the taxonomy of the Afrotropical Tetramorium weitzeckeri species complex (Hymenoptera, Formicidae, Myrmicinae), with the description of a new species from Kenya. European Journal of Taxonomy 90: 1-16. http://dx.doi.org/10.5852/ejt.2014.90

\section{Introduction}

The globally occurring myrmicine genus Tetramorium Mayr, 1855 is widespread throughout all zoogeographical regions and can be considered as hyper-diverse, with currently more than 545 valid species (Bolton 2013). It is a predominantly Old World genus with very few, mostly introduced, species found in the New World (Brown 1957; Bolton 1976, 1977, 1979, 1980; Hita Garcia et al. 2010). Its main distribution, with $c a .230$ described species, lies in the Afrotropical region, where species of Tetramorium occupy a wide range of habitats, microhabitats and lifestyles not seen in any other region, which suggests a likely origin or diversification centre within the Afrotropical region (Bolton 1976, 1980; Hita Garcia et al. 2010). The Malagasy Tetramorium fauna also shows a high degree of diversity, endemism, and often micro-endemism along its numerous isolated mountain ranges, but is less species-rich and holds much less morphological and ecological diversity than that of the Afrotropics. The combined and ongoing efforts of exhaustive inventories and large-scale revisions recently elevated the diversity in the Malagasy region from 39 species (Bolton 1979) to $c a$. 125 species (Hita Garcia \& Fisher 2011, 2012a, 2012b; FHG unpublished data). Due to its global distribution and hyper-diversity, new species of 
Tetramorium are continuously being discovered and described on a global level (e.g., Europe: Czösz et al. 2007; Csösz \& Schulz 2010; Central America: Vásquez-Bolaños 2007; Vásquez-Bolaños et al. 2011; Saudi Arabia: Sharaf et al. 2012; India: Bharti \& Kumar 2012), but the bulk of the undescribed diversity is expected from the Afrotropical region. Even though Bolton (1980) revised the whole Afrotropical region and synonymized the former genus Triglyphothrix Forel, 1890 with Tetramorium (Bolton 1985), many undescribed species have been discovered in field studies and in a score of museum collections by the authors (Hita Garcia et al. 2009, 2010, 2013, unpublished data). The taxonomy of two Afrotropical species groups was revised in recent years. In the first study twelve out of 26 species of the $T$. weitzeckeri group were described as new species (Hita Garcia et al. 2010), while the second described one additional species of the T. tortuosum group, raising the African species count to three (Hita Garcia \& Fisher 2013). With on-going taxonomic research and with additional material of undescribed species being generated by numerous field studies, we expect that the diversity of Tetramorium in the Afrotropical region is likely to reach 350 to 400 species in the future.

In 2009 and 2010 during the revision of the T. weitzeckeri species group (Hita Garcia et al. 2010) we became aware of a potentially new species collected by the late Roy R. Snelling (Natural History Museum of Los Angeles County, Los Angeles, U.S.A.) in Laikipia, Kenya (R.R. Snelling unpublished notes). Snelling wrote in his notes about a new species commonly collected on the ground at Mpala Research Centre, which looked morphologically very close to T. weitzeckeri Emery, 1895 and T. guineense (Bernard, 1953) but differing from them in petiolar node shape and pilosity on the first gastral tergite. During a research visit to the Snelling collection in 2009 we tried to find this material, which supposedly consisted of a few collections from the ground at Mpala Research Centre. Unfortunately, even after a thorough search through the collection, there was no undescribed T. weitzeckeri group species from Laikipia to be found anywhere, and the revision of the species group was finished without including that mysterious species. Surprisingly, during a recent examination of unidentified general Kenyan ant material collected by Snelling in 2001 at Mpala Research Centre, we encountered one specimen from an undescribed species belonging to the T. weitzeckeri species group. After a first examination it became apparent that it was indeed the new species mentioned by Snelling in his unpublished notes.

In this study we describe that new species as Tetramorium mpala sp. nov. and integrate it into the existing taxonomic system of the T. weitzeckeri species complex/group. Accordingly, we provide an illustrated identification key to the three species complexes of the T. weitzeckeri species group (T. edouardi complex, T. muralti complex, T. weitzeckeri complex) and an updated illustrated identification key to the species of the $T$. weitzeckeri species complex.

\section{Material and methods}

The collection abbreviations follow Evenhuis (2013). The material upon which this study is based is located and/or was examined at the following institutions:

$$
\begin{aligned}
& \text { BMNH }=\text { The Natural History Museum (British Museum, Natural History), London, U.K. } \\
& \text { CASC }=\text { California Academy of Sciences, San Francisco, California, U.S.A. } \\
& \text { LACM }=\text { Natural History Museum of Los Angeles County, Los Angeles, California, U.S.A. } \\
& \text { MCZ }=\text { Museum of Comparative Zoology, Cambridge, Massachusetts, U.S.A. } \\
& \text { MHNG }=\text { Muséum d'Histoire Naturelle de la Ville de Genève, Geneva, Switzerland } \\
& \text { NHMB = Naturhistorisches Museum, Basel, Switzerland } \\
& \text { ZFMK }=\text { Zoological Research Museum Alexander Koenig, Bonn, Germany }
\end{aligned}
$$

The only available specimen of T. mpala sp. nov. was deposited in the collection of LACM. Most of the material used for the recent revision of the whole T. weitzeckeri species group (Hita Garcia et al. 2010), especially the most recent collections, can be found in the collections of BMNH, CASC, LACM and ZFMK, while older type material is mostly located at BMNH, MCZ, MHNG and NHMB. The new type 
and all imaged specimens can be uniquely identified with specimen-level codes affixed to each pin (e.g., CASENT0247445).

Digital colour images of the new species were created using a Leica DFC 425 camera in combination with the Leica Application Suite software (version 3.8). All images presented are available online and can be consulted on AntWeb (http://www.antweb.org). The measurements were taken with a Leica MZ 12.5 equipped with an orthogonal pair of micrometers at a magnification of $100 \times$. Measurements are expressed in $\mathrm{mm}$ to two decimal places. The measurements and indices used in this study follow Hita Garcia \& Fisher (2011, 2012a, 2012b, 2013):

$\mathrm{HL}=$ Head length: maximum distance from the mid-point of the anterior clypeal margin to the mid-point of the posterior margin of the head, measured in full-face view. Impressions on anterior clypeal margin and posterior head margin reduce head length

$\mathrm{HW}=$ Head width: width of head directly behind the eyes measured in full-face view

$\mathrm{SL}=$ Scape length: maximum scape length excluding basal condyle and neck

$\mathrm{EL}=$ Eye length: maximum diameter of compound eye measured in oblique lateral view

$\mathrm{PH}=$ Pronotal height: maximum height of pronotum measured in lateral view

$\mathrm{PW}=$ Pronotal width: maximum width of pronotum measured in dorsal view

$\mathrm{WL}=$ Weber's length: diagonal length of mesosoma in lateral view from the postero-ventral margin of the propodeal lobe to the anterior-most point of the pronotal slope, excluding the neck

PSL = Propodeal spine length: the tip of the measured spine, its base, and the centre of the propodeal concavity between the spines must all be in focus. Using a dual-axis micrometer the spine length is measured from the tip of the spine to a virtual point at its base where the spine axis meets orthogonally with a line leading to the median point of the concavity

PTH = Petiolar node height: maximum height of petiolar node measured in lateral view from the highest (median) point of the node to the ventral outline. The measuring line is placed at an orthogonal angle to the ventral outline of the node

PTL = Petiolar node length: maximum length of the dorsal face of the petiolar node from the anterodorsal to the posterodorsal angle measured in dorsal view

PTW = Petiolar node width: maximum width of dorsal face of petiolar node measured in dorsal view

$\mathrm{PPH}=$ Postpetiole height: maximum height of the postpetiole measured in lateral view from the highest (median) point of the node to the ventral outline. The measuring line is placed at an orthogonal angle to the ventral outline of the node

PPL = Postpetiole length: maximum length of postpetiole measured in dorsal view

PPW $=$ Postpetiole width: maximum width of postpetiole measured in dorsal view

$\mathrm{OI}=$ Ocular index $(\mathrm{EL} / \mathrm{HW} \times 100)$

$\mathrm{CI}=$ Cephalic index $(\mathrm{HW} / \mathrm{HL} \times 100)$

SI $=$ Scape index $(\mathrm{SL} / \mathrm{HW} \times 100)$

$\mathrm{DMI}=$ Dorsal mesosoma index $(\mathrm{PW} / \mathrm{WL} \times 100)$

LMI $=$ Lateral mesosoma index $(\mathrm{PH} / \mathrm{WL} \times 100)$

PSLI $=$ Propodeal spine index $(\mathrm{PSL} / \mathrm{HL} \times 100)$

$\mathrm{PeNI}=$ Petiolar node index $(\mathrm{PTW} / \mathrm{PW} \times 100)$

LPeI $=$ Lateral petiole index $(\mathrm{PTL} / \mathrm{PTH} \times 100)$

DPeI $=$ Dorsal petiole index $(\mathrm{PTW} / \mathrm{PTL} \times 100)$

$\mathrm{PpNI}=$ Postpetiolar node index $(\mathrm{PPW} / \mathrm{PW} \times 100)$

$\mathrm{LPpI}=$ Lateral postpetiole index $(\mathrm{PPL} / \mathrm{PPH} \times 100)$

$\mathrm{DPpI}=$ Dorsal postpetiole index $(\mathrm{PPW} / \mathrm{PPL} \times 100)$

PPI $=$ Postpetiole index $(\mathrm{PPW} / \mathrm{PTW} \times 100)$ 
Note that the petiole and postpetiole were measured differently. For the petiole, only the petiolar node was measured, excluding the peduncle, as the node has proved to be of high diagnostic value (Hita Garcia et al. 2010). Measurements of the whole petiole, peduncle plus node, would mask these important differences between species. In contrast, we measured the whole postpetiole because it was rounded in most species and without a distinct peduncle-like structure. As a consequence, some information can be lost in the few species with a moderately or strongly anteroposteriorly compressed postpetiole. Even so, the postpetiole measurements as defined still permit better comparisons for most species.

Pubescence and pilosity are usually of high diagnostic value within the genus Tetramorium (e.g., Bolton 1976, 1980; Hita Garcia et al. 2010, Hita Garcia \& Fisher 2011, 2012a, 2012b). The varying degree of inclination of pilosity is particularly important for the diagnoses of groups or species. In this context we use the terms 'erect', 'suberect', 'subdecumbent', 'decumbent', and 'appressed' following Wilson (1955).

\section{Results}

\section{Identification key to Afrotropical species complexes of the T. weitzeckeri species group (workers)}

In Hita Garcia et al. (2010) we provided a key to all species from all three species complexes without a special key to these complexes. In order to facilitate species identifications and species group placements in the future, we provide a simple key to the complexes here:

1. Antennal scrobe well developed and usually deep, with a distinct and often sharp margin all around, frontal carinae curve down ventrally between posterior eye level and occipital margin to form the posterior and ventral margins of the antennal scrobe, in a few species posterior margin weak but still
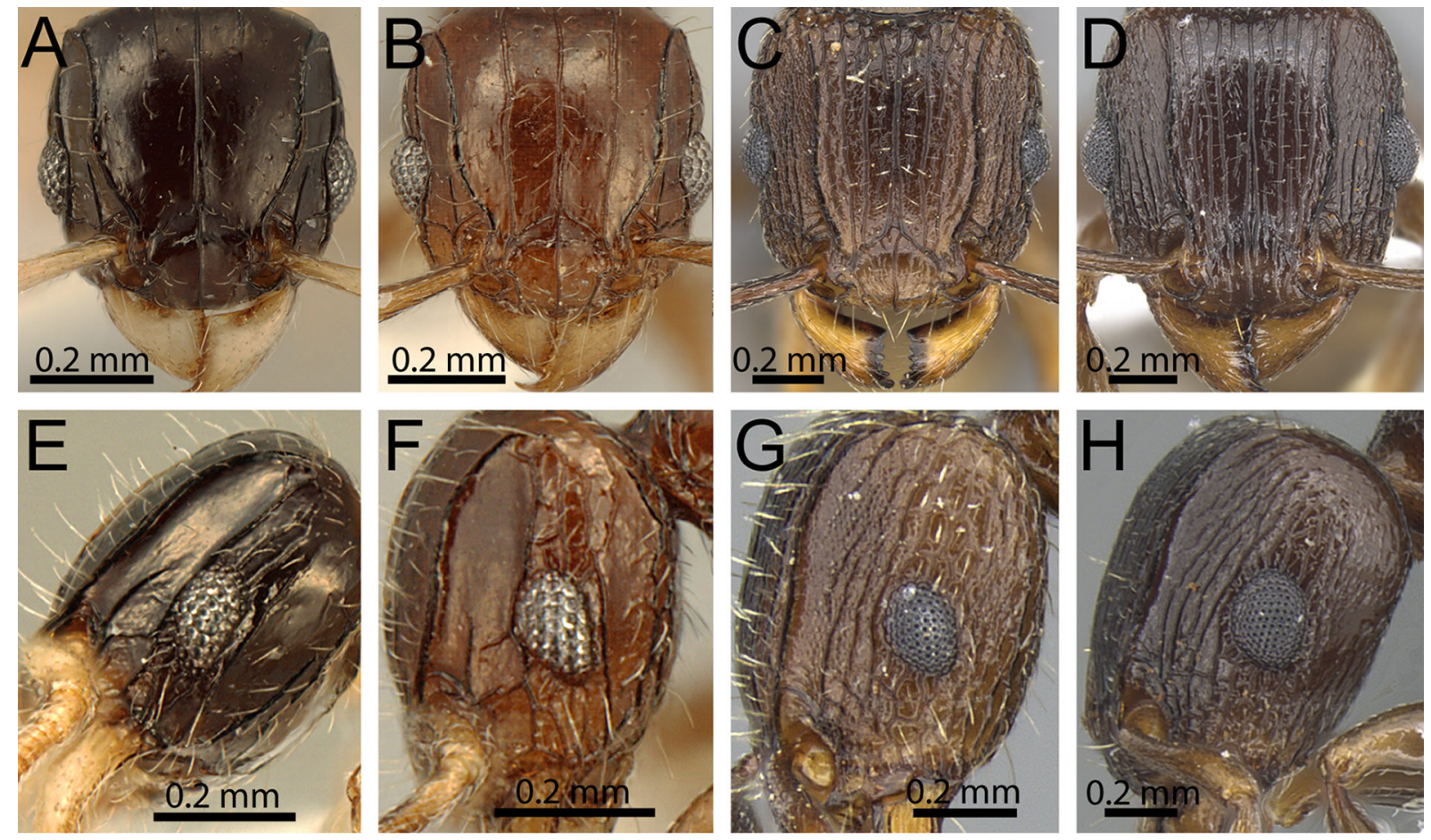

Fig. 1. Head in frontal and lateral views. A, E. Tetramorium flavithorax (Santschi, 1914) (ZFMKHYM20096172). B, F. T. muralti Forel, 1910 (ZFMKHYM20096125). C, G. T. weitzeckeri Emery (CASENT0249013, AntWeb, R. Perry 2011). D, H. T. mkomazi Hita Garcia, Fischer \& Peters, 2010 (ZFMKHYM20096087). 
HITA GARCIA F. \& FISCHER G., Taxonomy of the Afrotropical Tetramorium weitzeckeri complex

visible; sculpture on cephalic dorsum often reduced, generally 3 or fewer rugae present between frontal carinae, in a few species up to 5 or 6 , never more (Fig. 1A-B, E-F) ......T. muralti complex

- Antennal scrobe developed, but shallow, never with a sharp margin all around, frontal carinae almost reaching occipital margin and functioning as dorsal margin of antennal scrobe, ventral margin of antennal scrobe never differentiated; sculpture on cephalic dorsum never reduced, always at least 7 (generally distinctly more) longitudinal rugae present between frontal carinae (Fig. 1D, G-H) ........2

2. Petiolar node distinctly squamiform, in profile between 2.3 and 4.0 times higher than long (LPeI 25-43), shape in dorsal view always strongly transverse and elliptical, and between 2.2 and 3.7 times wider than long (DPeI 219-367) (Fig. 2A-B, E-F) .........T. weitzeckeri complex

- Petiolar node high nodiform, in profile around 1.3 to 2.0 times higher than long (LPeI 50-80), shape in dorsal view never elliptical or transverse, more an irregular polygon with rounded corners, and between 1.1 and 1.5 times wider than long(DPeI 110-154)(Fig. 2C-D, G-H) ......T. edouardi complex

\section{Synopsis of Afrotropical T. weitzeckeri species complex}

Tetramorium bendai Hita Garcia, Fischer \& Peters, 2010

Tetramorium boltoni Hita Garcia, Fischer \& Peters, 2010

Tetramorium guineense (Bernard, 1953)

Tetramorium humbloti Forel, 1891

= Tetramorium humbloti pembensis Forel, 1907

= Tetramorium humbloti victoriensis Forel, 1913

Tetramorium mpala Hita Garcia \& Fischer sp. nov.

Tetramorium renae Hita Garcia, Fischer \& Peters, 2010

Tetramorium sepultum Bolton, 1980

Tetramorium snellingi Hita Garcia, Fischer \& Peters, 2010
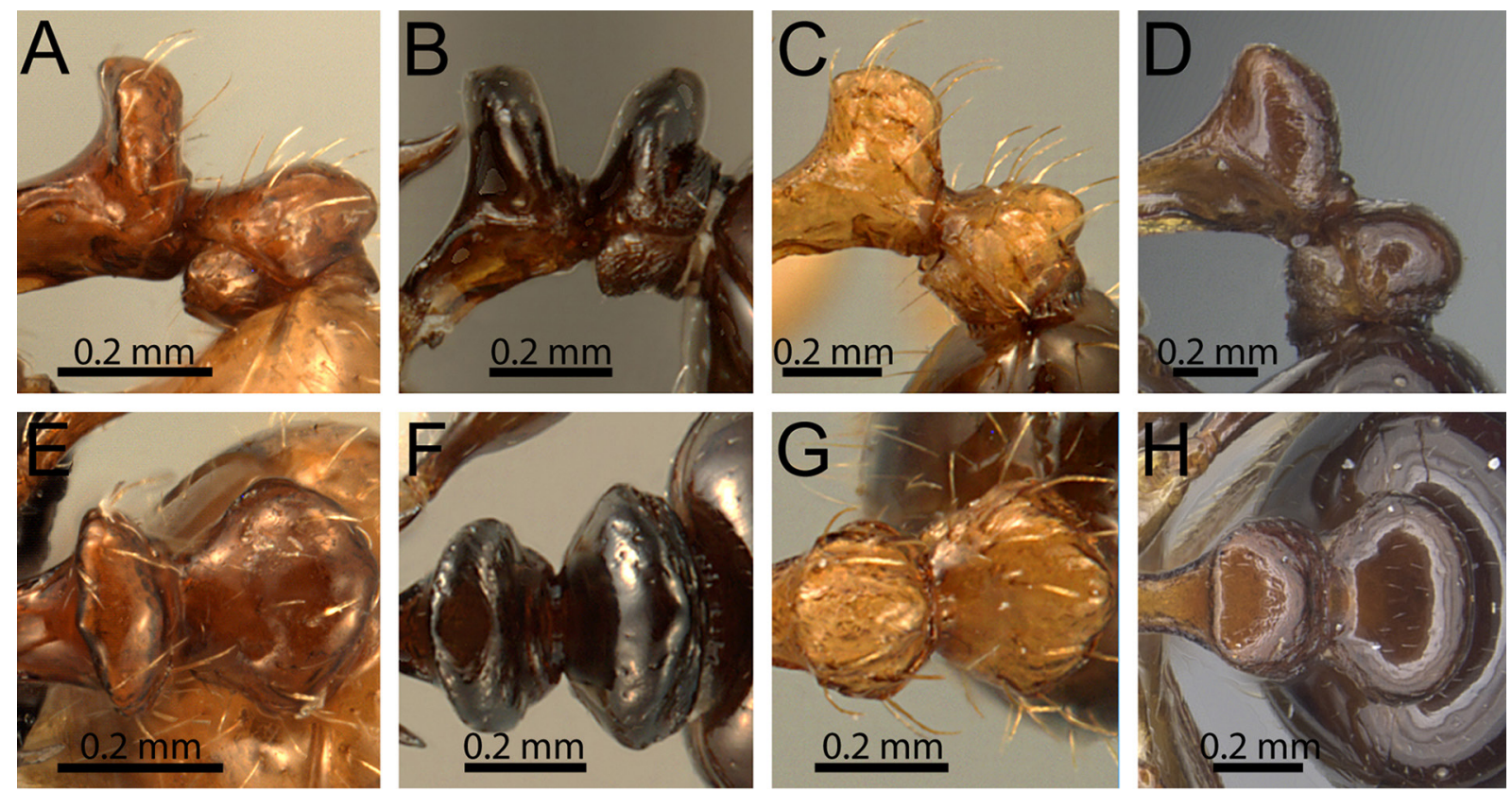

Fig. 2. Petiolar node in lateral and dorsal views. A, E. Tetramorium renae Hita Garcia, Fischer \& Peters (CASENT0095412). B, F. T. bendai Hita Garcia, Fischer \& Peters (ZFMKHYM20096204). C, G. T. philippwagneri Hita Garcia, Fischer \& Peters, 2010 (ZFMKHYM20096178). D, H. T. mkomazi Hita Garcia, Fischer \& Peters, 2010 (ZFMKHYM20096087). 
Tetramorium tanaense Hita Garcia, Fischer \& Peters, 2010

Tetramorium weitzeckeri Emery, 1895

= Tetramorium ebeninum Arnold, 1926

$=$ Tetramorium escherichi Forel, 1910

= Tetramorium weitzeckeri edithae (Weber, 1943)

= Tetramorium weitzeckeri nigellus (Santschi, 1932)

\section{Notes on biogeography and identification}

New material has become available since the last revision of the T. weitzeckeri species group (Hita Garcia et al. 2010); subsequently, the distribution ranges of a few species need to be adjusted. Fresh material from an ongoing inventory of the ant fauna of Gorongosa National Park in Mozambique revealed the presence of $T$. humbloti, $T$. sepultum and T. weitzeckeri. Even though their presence in Mozambique is not surprising, all three were previously unknown from that country. Hita Garcia et al. (2010) reported the absence of T. humbloti from Kenya, but some freshly identified material from the area around Nairobi clearly belongs to this species. The distribution range of T. tanaense is also larger than previously understood. It is now known from the forest of Arabuko Sokoke on the Kenyan coast, which is close to the type locality, and from Ndimba Forest Reserve located in south-eastern Tanzania close to the Indian Ocean.

Despite these new findings, the biogeographic composition of the complex has not changed significantly. Tetramorium boltoni, T. guineense, T. renae and T. snellingi are species found predominantly in the equatorial rainforest belt, whereas the species T. humbloti, T. sepultum and T. weitzeckeri are distributed in the drier eastern and southern parts of sub-Saharan Africa. Tetramorium tanaense seems to be endemic to the coastal forests of Eastern Africa in Kenya and Tanzania, and T. bendai is only known from one collection in Burundi (without any ecological information at all). Tetramorium mpala sp. nov. also seems to have a very restricted distribution because it is only known from its type locality in Central Kenya.

In addition, several non-taxonomists have used the identification key published in Hita Garcia et al. (2010) and, fortunately, provided feedback to us. The key seemed to have worked mostly well, but users drew attention to some problems in the key not anticipated back in 2010. These problems were mainly located in the part of the key dealing with the $T$. weitzeckeri species complex, especially the separation
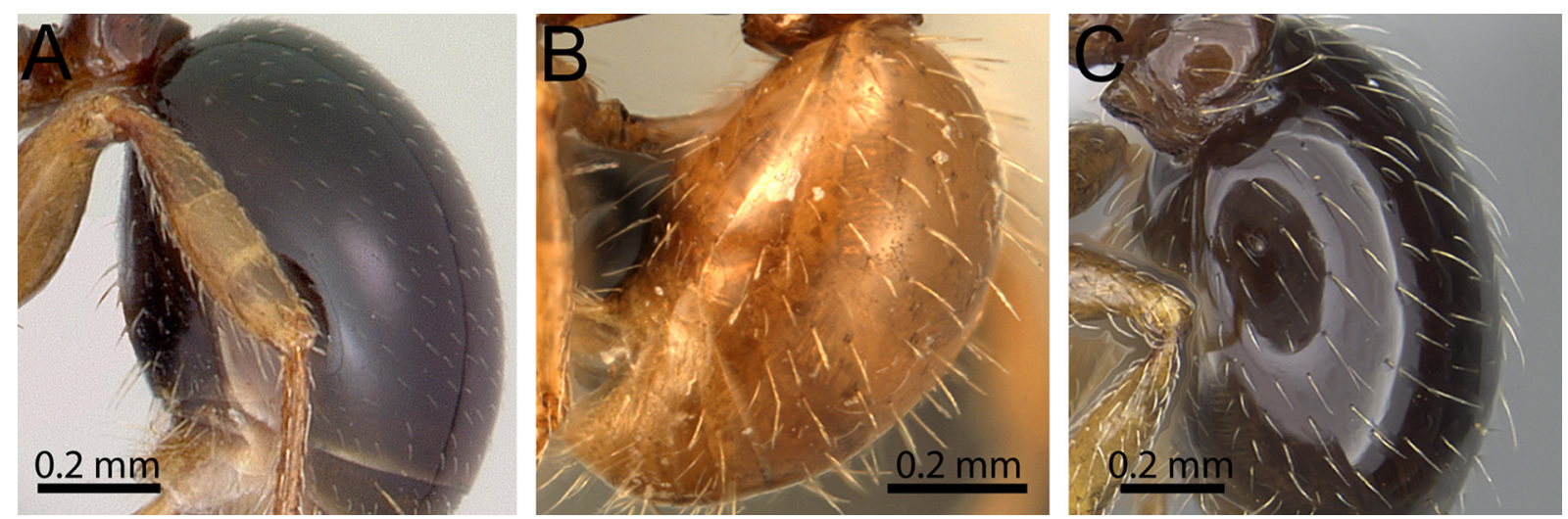

Fig. 3. Gaster in lateral view. A. Tetramorium humbloti Forel (CASENT0059691, AntWeb, April Nobile 2006). B. T. renae Hita Garcia, Fischer \& Peters (CASENT0095412). C. T. mpala sp. nov. (CASENT0247445, AntWeb, M. Esposito 2013). 

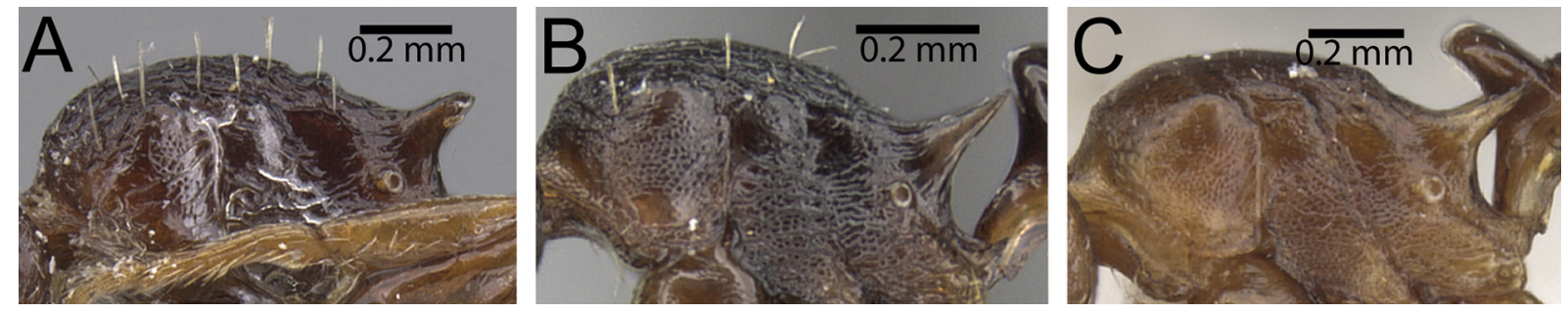

Fig. 4. Mesosoma in lateral view. A. Tetramorium sepultum Bolton (CASENT0901160, AntWeb, W. Ericson 2011). B. T. tanaense Hita Garcia, Fischer \& Peters (CASENT0235815, AntWeb, R. Perry 2011). C. T. humbloti Forel (CASENT0900677, AntWeb, W. Ericson 2011).

of T. guineense from T. weitzeckeri. Some series of the latter species from Tanzania and South Africa possess strongly developed cephalic ground sculpture almost as distinct as seen in $T$. guineense, which causes difficulties with the key, even though both species are certainly not conspecific and differ in various aspects. Consequently, we have modified the identification key to include these users' first-hand experience in order to make the discrimination of $T$. guineense from $T$. weitzeckeri easier, as well as several other minor changes throughout the key.

\section{Identification key to species of the $T$. weitzeckeri species complex (workers)}

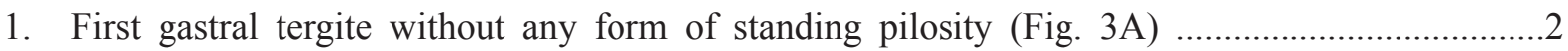

- First gastral tergite with standing pilosity (Fig. 3B-C) …….................................................

2. Mesosoma with abundant long, erect hairs (usually 7 to 8 pairs of hairs) (Fig. 4A) [Mozambique, Tanzania, South Africa, Swaziland] ..T. sepultum

- Mesosoma usually without long, erect hairs, rarely with up to 4 pairs of hairs at most (Fig. 4B-C) ...3

3. Whole mesosoma covered with fine, mostly longitudinal rugulae superimposed on a very distinct reticulate-punctate ground sculpture (Fig. 5A) [Burundi]

T. bendai

- Mesosoma either mostly unsculptured or rugulose, often in parts with weakly punctate ground sculpture, but never fully covered with distinct reticulate-punctate ground sculpture as above (Fig. $5 \mathrm{~B}-\mathrm{C})$ .4
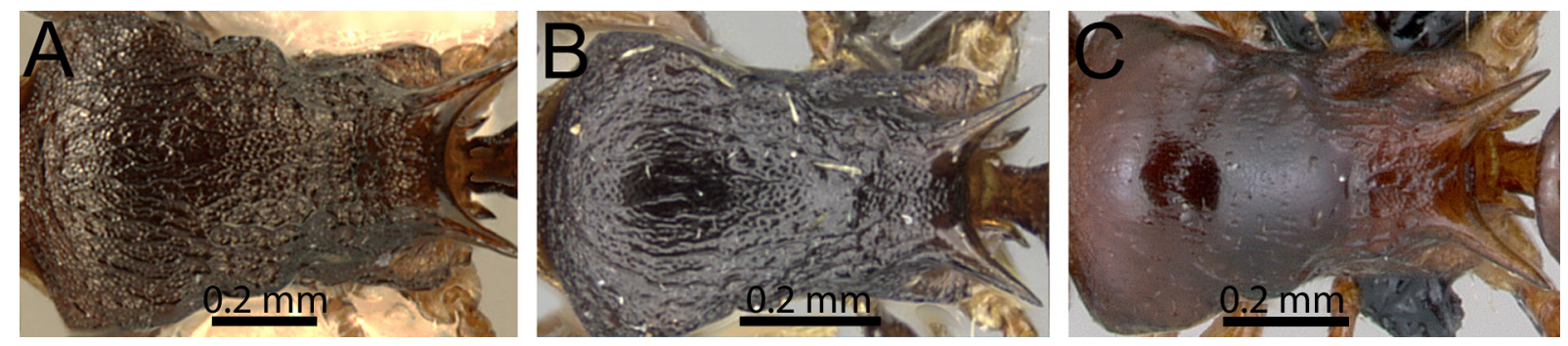

Fig. 5. Mesosoma in dorsal view. A. Tetramorium bendai Hita Garcia, Fischer \& Peters (ZFMKHYM20096204). B. T. tanaense Hita Garcia, Fischer \& Peters (CASENT0235815, AntWeb, R. Perry 2011). C. T. humbloti Forel (CASENT0059691, AntWeb, A. Nobile 2006). 
4. Most of mesosomal dorsum, especially pronotum, noticeably longitudinally rugulose (Fig. 5B) [Kenya, Tanzania] .....

T. tanaense

- Dorsum of mesosoma, especially pronotum, unsculptured and shiny (Fig. 5C) [Comoros, Kenya, Madagascar, Mauritius, Mayotte, Mozambique, Namibia, South Africa, Tanzania, Zambia, Zimbabwe]

T. humbloti

5. Eyes very large (OI 31); first gastral tergite with long, decumbent to subdecumbent (rarely appressed) pilosity [Kenya] (Fig. 6A, D)

T. mpala sp. nov.

- Eyes always smaller than above (OI 16-26); first gastral tergite with long suberect to erect pilosity (Fig. 6B-C, E-F)

6. Dorsum of head with conspicuous reticulate-punctate ground sculpture; postpetiole in profile between 1.3 and 1.7 times higher than long (LPpI 59-75) and in dorsal view around 1.4
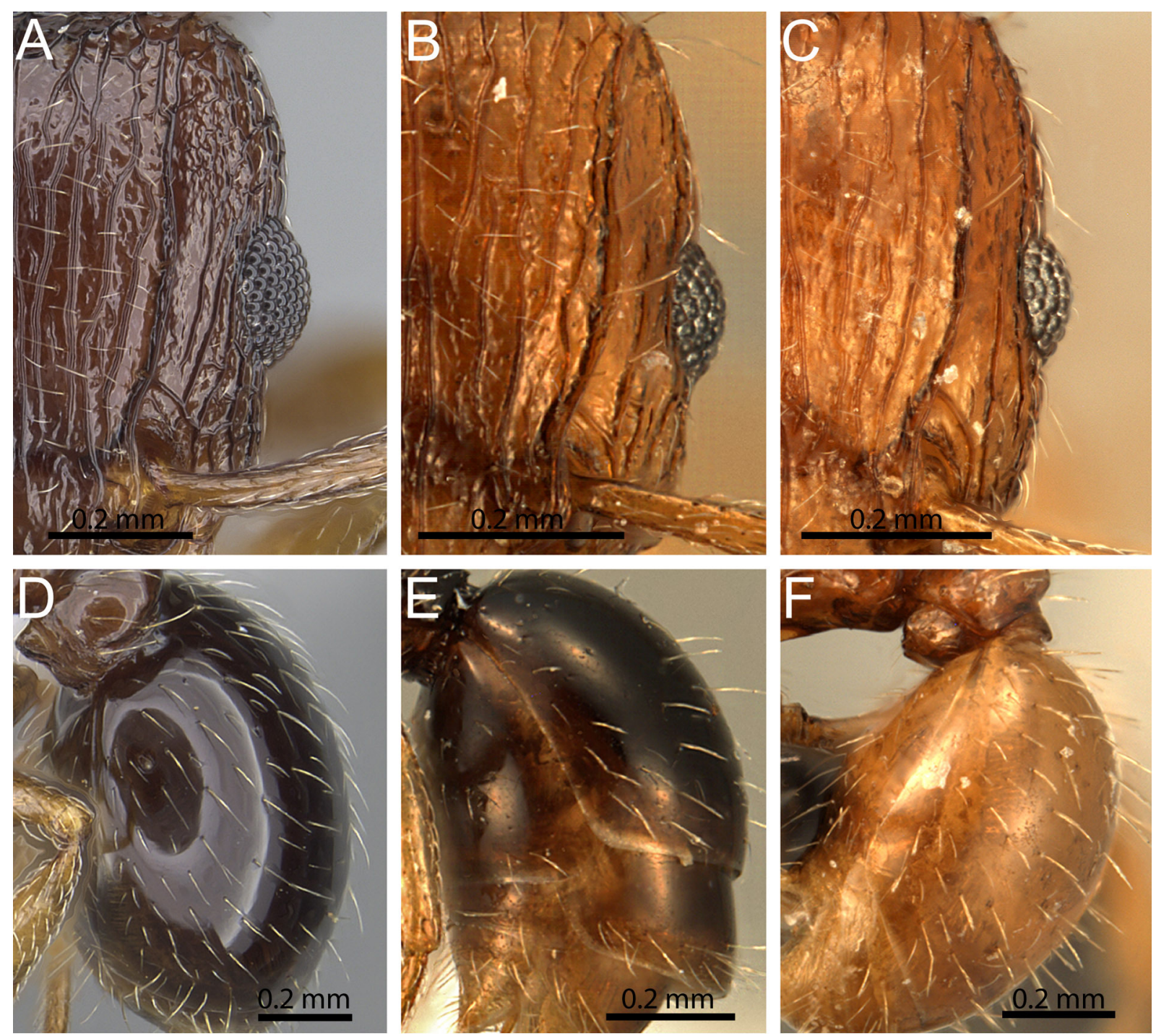

Fig. 6. Half of head in frontal view and gaster in lateral view. A, D. Tetramorium mpala sp. nov. (CASENT0247445, AntWeb, M. Esposito 2013). B, E. T. snellingi Hita Garcia, Fischer \& Peters (ZFMK-HYM20093102). C, F. T. renae Hita Garcia, Fischer \& Peters (CASENT0095412). 

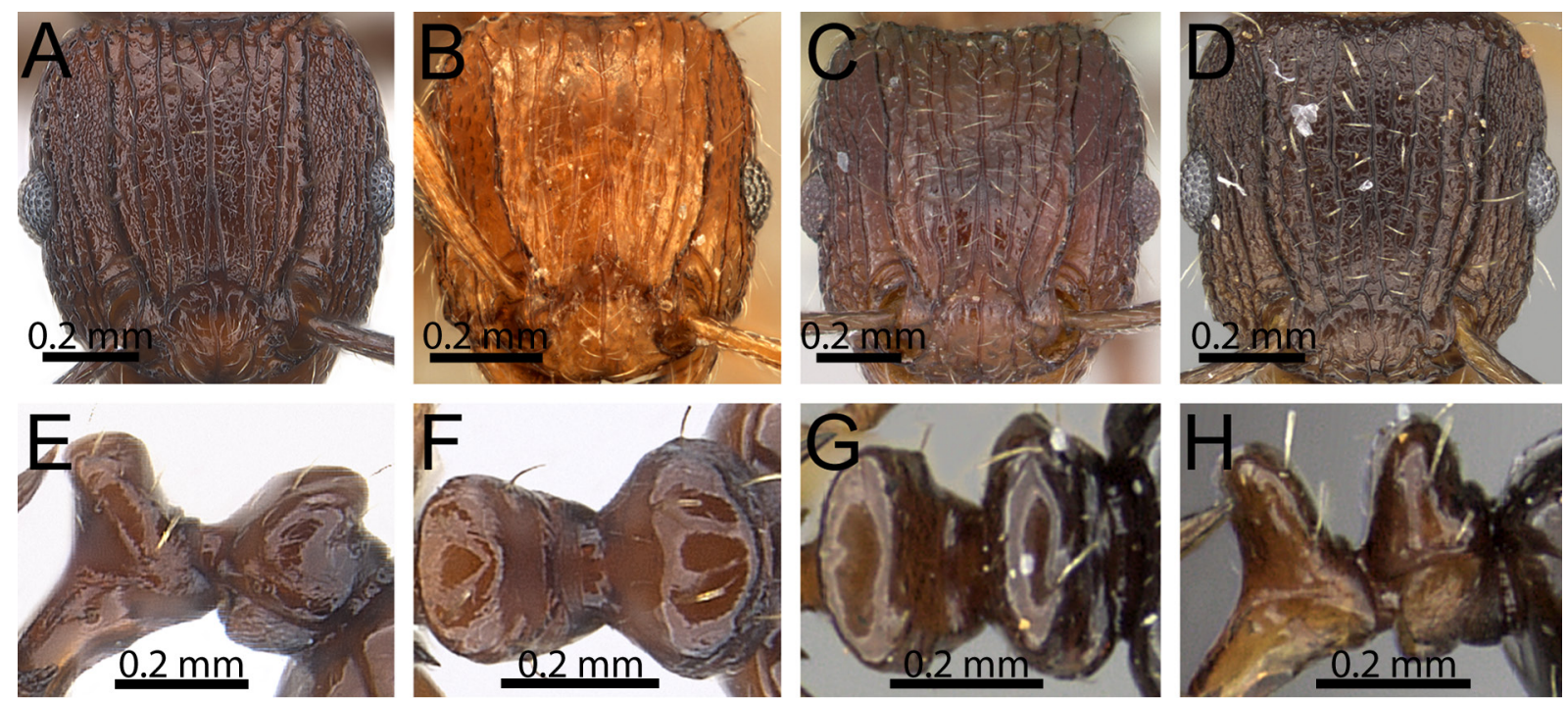

Fig. 7. Head in frontal view and waist segments in dorsal view. A, E-F. Tetramorium guineense (Bernard) (CASENT0217061, AntWeb, E. Prado 2011). B. T. renae Hita Garcia, Fischer \& Peters (CASENT0095412). C-D, G-H. T. weitzeckeri Emery (CASENT0103295 \& CASENT0235814, AntWeb, A. Nobile 2006 \& R. Perry 2011).

to 1.5 times wider than long (DPpI 137-154) (Fig. 7A, E-F) [Cameroon, Central African Republic, D.R. Congo, Gabon, Ghana, Guinea, Ivory Coast, Liberia, Nigeria] .......T. guineense

- Character combination never as above; dorsum of head usually without conspicuous reticulatepunctate ground sculpture; if cephalic ground sculpture noticeably reticulate-punctate (as in some series of T. weitzeckeri), then postpetiole in profile around 1.7 to 2.1 times higher than long (LPpI 49-60) and in dorsal view 1.7 to 2.0 times wider than long (DPpI 146-203) (Fig. 7B-D, G-H) ......7

7. Distinctly bicoloured species, head and mesosoma orange to reddish brown, petiole, postpetiole and gaster very dark brown to black (Fig. 8A) [Central African Republic, Kenya, Uganda] ...T. snellingi

- Whole body either uniformly brown to black or bicoloured with gaster, and often head, of lighter colour than mesosoma, petiole, and postpetiole (Fig. 8B-C)

8. Species either bicoloured, with gaster, appendages and head yellowish brown contrasting with reddish brown mesosoma, petiole and postpetiole, or whole body dark brown to black; mesosomal sculpture partly reduced, dorsum generally with weak longitudinal rugulae only,
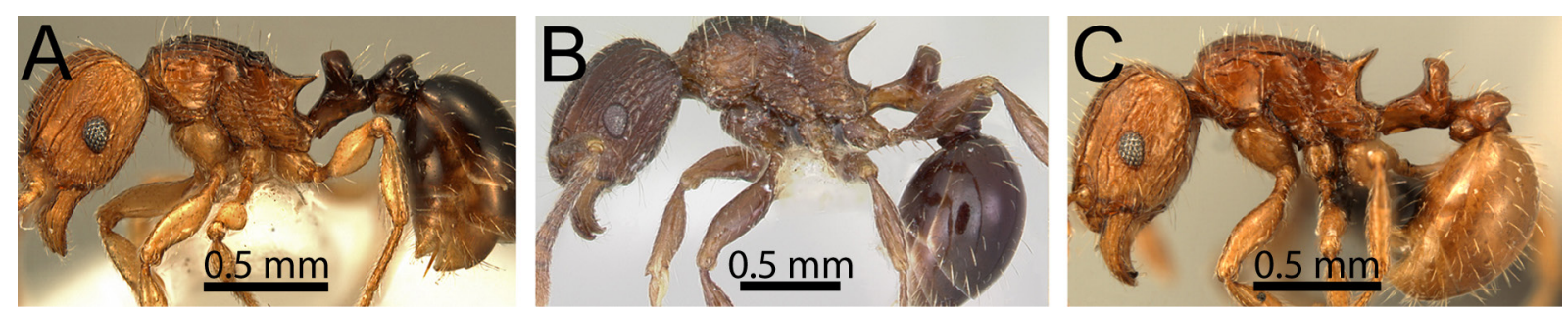

Fig. 8. Body in lateral view. A. Tetramorium snellingi Hita Garcia, Fischer \& Peters (ZFMKHYM20093102, E. Wiesel). B. T. weitzeckeri Emery (CASENT0103295, AntWeb, A. Nobile 2006). C. T. renae Hita Garcia, Fischer \& Peters (CASENT0095412). 

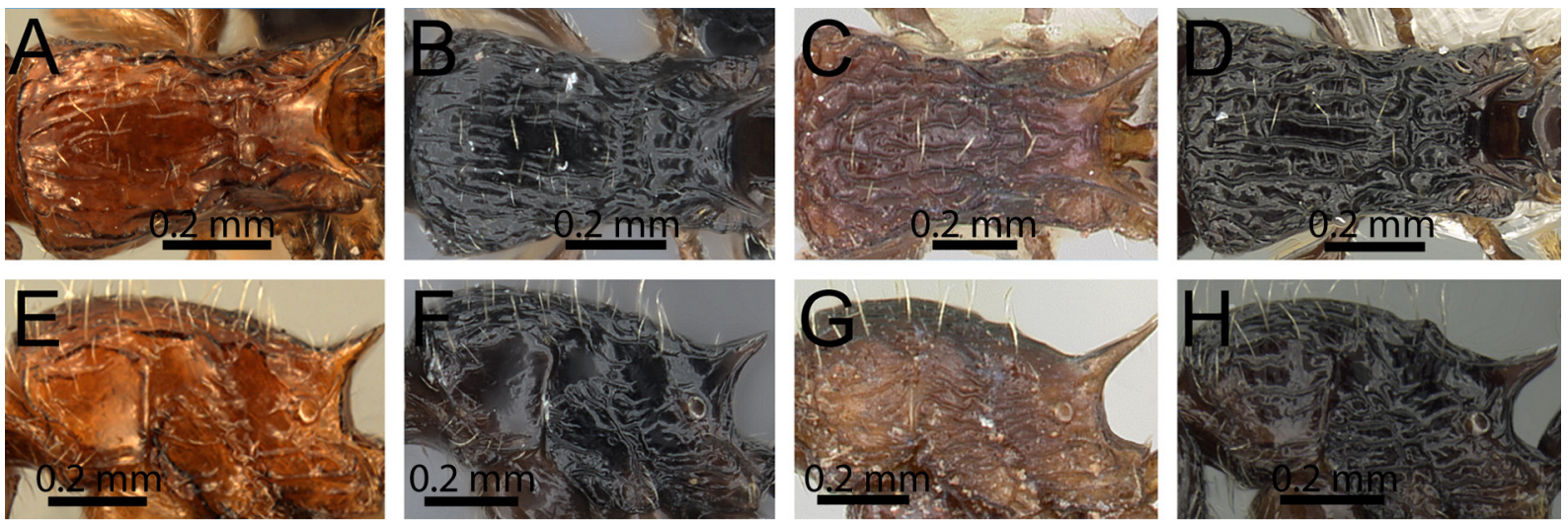

Fig. 9. Mesosoma in dorsal and lateral views. A, E. Tetramorium renae Hita Garcia, Fischer \& Peters - light brown form (CASENT0095412). B, F. T. renae Hita Garcia, Fischer \& Peters - dark brown form (CASENT0095421, AntWeb, W. Ericson 2011). C, G. T. weitzeckeri Emery (CASENT0103295, AntWeb, A. Nobile 2006). D, H. T. boltoni Hita Garcia, Fischer \& Peters (CASENT0217229, AntWeb, R. Perry 2011).

lateral mesosoma to great extent unsculptured; ground sculpture on lateral and dorsal mesosoma absent, appearing smooth and shining (Figs 8C, 9A-B, E-F) [São Tomé \& Principe] .......T. renae

- Uniformly coloured species, generally dark brown to black; usually with mesosoma dorsally and laterally strongly longitudinally rugose, very rarely with weaker developed rugae or rugulae, in the latter case the ground sculpture is reticulate-punctate (Figs $8 B, 9 \mathrm{C}-\mathrm{D}, \mathrm{G}-\mathrm{H}$ )

9. Larger species (HW 0.77-0.93; HL 0.79-0.94; SL 0.60-0.74; WL 0.91-1.21); propodeal spines long to very long and spinose (PSLI 32-45); body colouration ranging from light brown to almost black, but usually of lighter brown than below; dry forest or savannah species (Figs 9G, 10A) [Angola, Eritrea, Kenya, Mozambique, Namibia, South Africa, Sudan, Swaziland, Tanzania, Zambia, Zimbabwe]

T. weitzeckeri

- Smaller species (HW 0.64-0.74; HL 0.68-0.76; SL 0.47-0.54; WL 0.78-0.91); propodeal spines moderate to long, triangular-elongate to spinose, but never as long as above (PSLI 2329); body colouration always very dark brown to black; rainforest species (Figs 9H, 10B) [Angola, Cameroon, Central African Republic, D.R. Congo, Equatorial Guinea, Gabon, Kenya, Nigeria, Uganda, Sudan]

T. boltoni
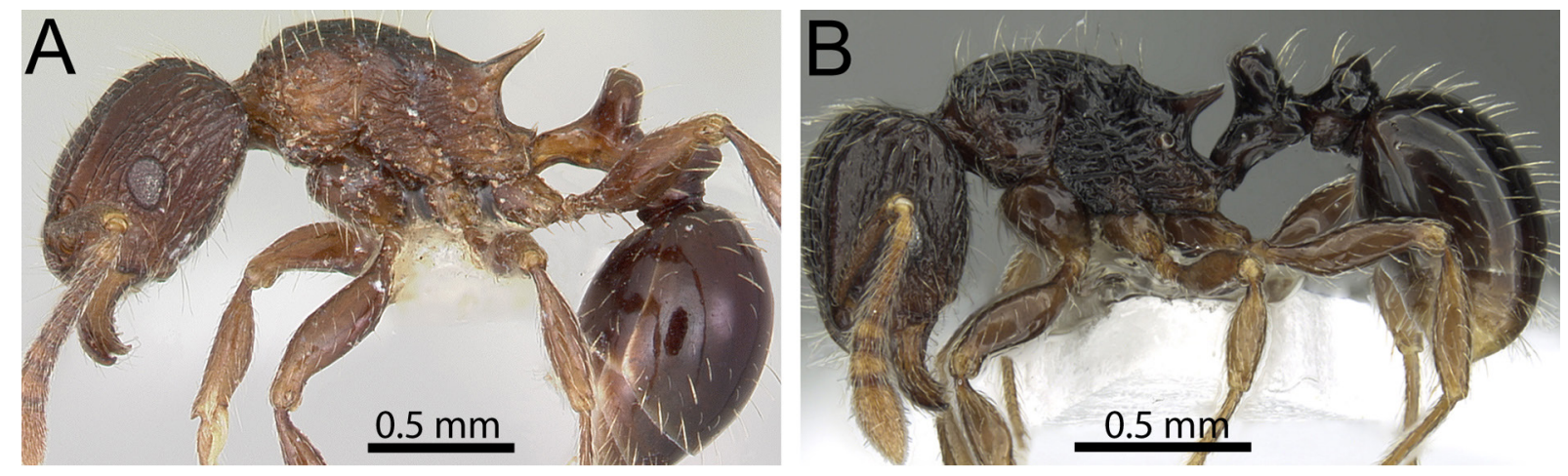

Fig. 10. Body in lateral view. A. Tetramorium weitzeckeri Emery (CASENT0103295, AntWeb, A. Nobile 2006). B. T. boltoni Hita Garcia, Fischer \& Peters (ZFMKHYM20096155). 
Tetramorium mpala sp. nov. urn:1sid:zoobank.org:act:97CF15C9-2859-4075-9A6A-F0A82023BA3A

Figs 3C, 6A, D, 11, 12

\section{Type material}

\section{Holotype}

KENYA: Pinned worker, Rift Valley Province, Laikipia District, Mpala Research Centre, $0.29^{\circ} \mathrm{S}$, $36.9^{\circ} \mathrm{E}, 1650 \mathrm{~m}$, Acacia woodland, foraging on ground, collection code RRS01-188, 2 Apr. 2001, R.R. Snelling, unique specimen identifier CASENT0247445 (LACM).

\section{Diagnosis}

The character combination of very large eyes (OI 31) and first gastral tergite with long, fine decumbent to subdecumbent (rarely appressed) pilosity distinguishes T. mpala from the remainder of the $T$. weitzeckeri species complex.

\section{Description (worker, $\mathrm{N}=1$ )}

Measurements: HL 0.79; HW 0.74; SL 0.60; EL 0.23; PH 0.44; PW 0.59; WL 1.04; PSL 0.28; PTL 0.12; PTH 0.36; PTW 0.35; PPL 0.26; PPH 0.38; PPW 0.42; CI 94; SI 71; OI 31; DMI 57; LMI 42; PSLI 35; PeNI 59; LPeI 33; DPeI 292; PpNI 71; LPpI 68; DPpI 162; PPI 120.

Head longer than wide (CI 94); posterior head margin in full-face view flat to weakly concave; anterior clypeal margin with distinct median impression; frontal carinae strongly developed, distinctly raised, and very long, approaching or ending at posterior head margin; antennal scrobes present, but shallow and without clearly defined posterior and ventral margins. Antennal scapes of moderate length, not reaching posterior head margin (SI 81). Eyes very large (OI 31).

Mesosomal outline in profile weakly to moderately convex, moderately marginate from lateral to dorsal mesosoma, comparatively high and stout (LMI 42); promesonotal suture present, weak but clearly visible; metanotal groove well developed and in profile moderately deep. Propodeal spines long, spinose and acute (PSLI 35); propodeal lobes short, triangular and blunt. Petiolar node squamiform to thinly high cuneiform and slightly triangular, in profile three times higher than long (LPeI 33), anterodorsal and posterodorsal margins relatively rounded and posterodorsal margin less well developed than anterodorsal, petiolar dorsum tapering backwards; node in dorsal view of strongly transverse elliptical shape, around 2.9 times as wide as long (DPeI 292). Postpetiole in profile subglobular to weakly anteroposteriorly compressed, approximately 1.5 times as high as long (LPpI 68); in dorsal view around 1.6 times as wide as long (DPpI 162). Postpetiole in profile appearing higher and more voluminous than petiolar node, in dorsal view 1.2 times as wide as petiolar node (PPI 120).

Mandibles striate; clypeus longitudinally rugulose with six more or less irregular rugulae, median rugula not well developed; cephalic dorsum between frontal carinae irregularly longitudinally rugose with around eight rugae, rugae running from posterior clypeal margin to posterior head margin, but some broken, meandering or with cross-meshes; scrobal area partly unsculptured, but mostly merging with surrounding reticulate-rugose to longitudinally rugose sculpture present on lateral and ventral. Mesosoma laterally and dorsally longitudinally rugose, laterally slightly more irregularly so. Forecoxae unsculptured, smooth and shining. Both waist segments and gaster completely unsculptured, smooth and shining. Ground sculpture generally faint to absent everywhere on body. Head with moderately abundant standing pilosity; mesosoma with six pairs of long, fine, standing hairs; petiole with three pairs of long, fine, standing hairs and postpetiole with four pairs of subdecumbent to decumbent, long, fine hairs; first gastral tergite with fairly long, fine and subdecumbent to decumbent pilosity. Anterior edges 

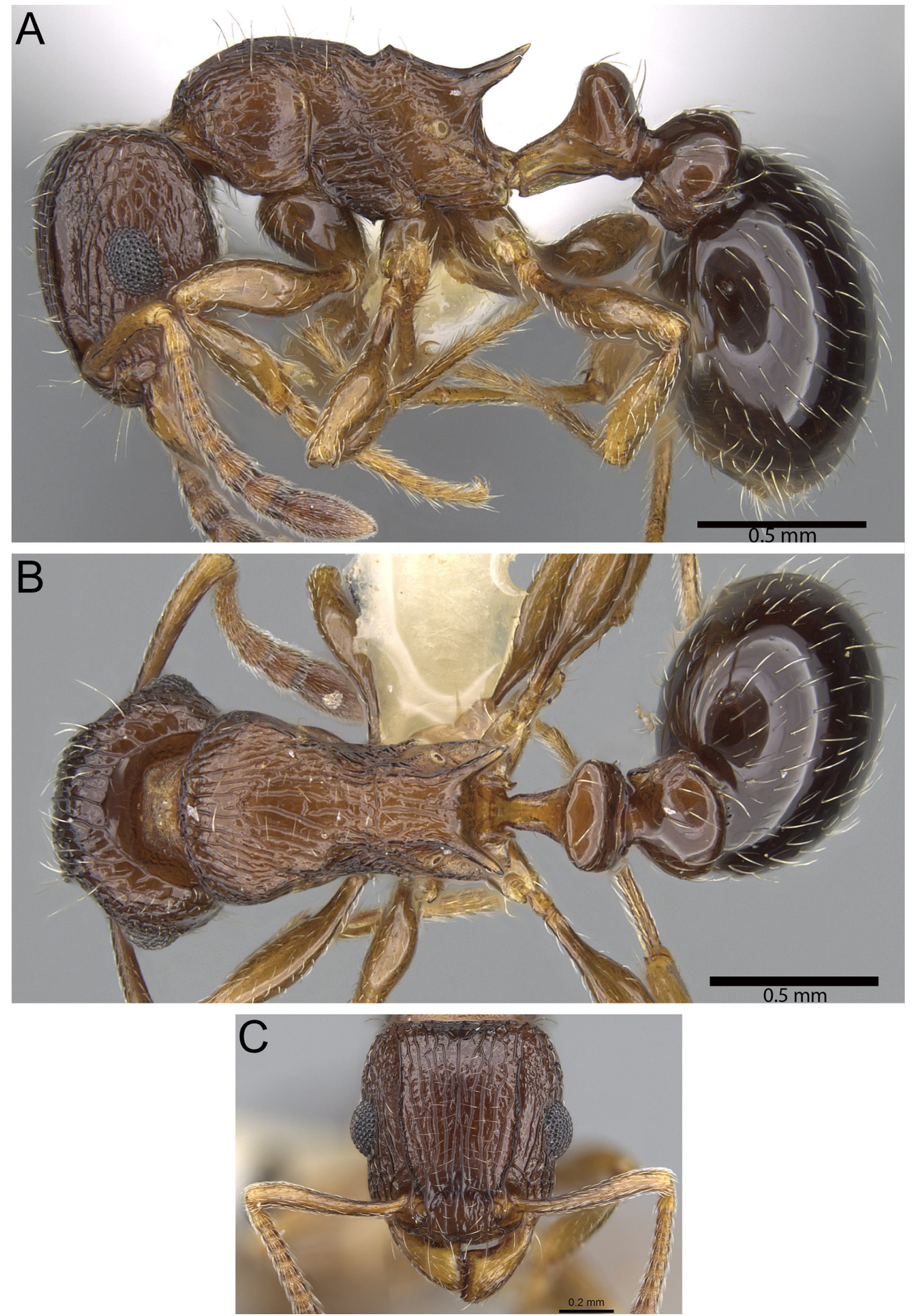

Fig. 11. Tetramorium mpala sp. nov. (CASENT0316967). A. Body in lateral view. B. Body in dorsal view. C. Head in frontal view. 
of antennal scapes and metatibiae with appressed hairs. Body colouration chestnut brown to dark brown, appendages lighter in colour and gaster much darker than remainder of body.

\section{Etymology}

The name of the new species is inspired by the type locality, the Mpala Research Centre, which is an important research facility in Kenya. The species epithet is a nominative noun in apposition and thus invariant.

\section{Distribution and ecology}

Tetramorium mpala sp. nov. is currently only known from the type locality (Fig. 12) where it was collected in acacia woodland savannah at an elevation of $1650 \mathrm{~m}$. The holotype was sampled on the ground, but until more material becomes available it remains unclear whether that is the primary stratum of T. mpala.

\section{Discussion}

The new species is readily distinguishable within the T. weitzeckeri species complex. The most obvious character is certainly the pilosity on the first gastral tergite, which is long, fine and subdecumbent to decumbent in T. mpala sp. nov., whereas the remainder of the complex either lacks any long pilosity at all (T. bendai, T. humbloti, T. sepultum and T. tanaense) or possesses long, suberect to erect pilosity (T. boltoni, T. guineense, T. renae, $T$. snellingi and $T$. weitzeckeri). The second-best character is eye size,

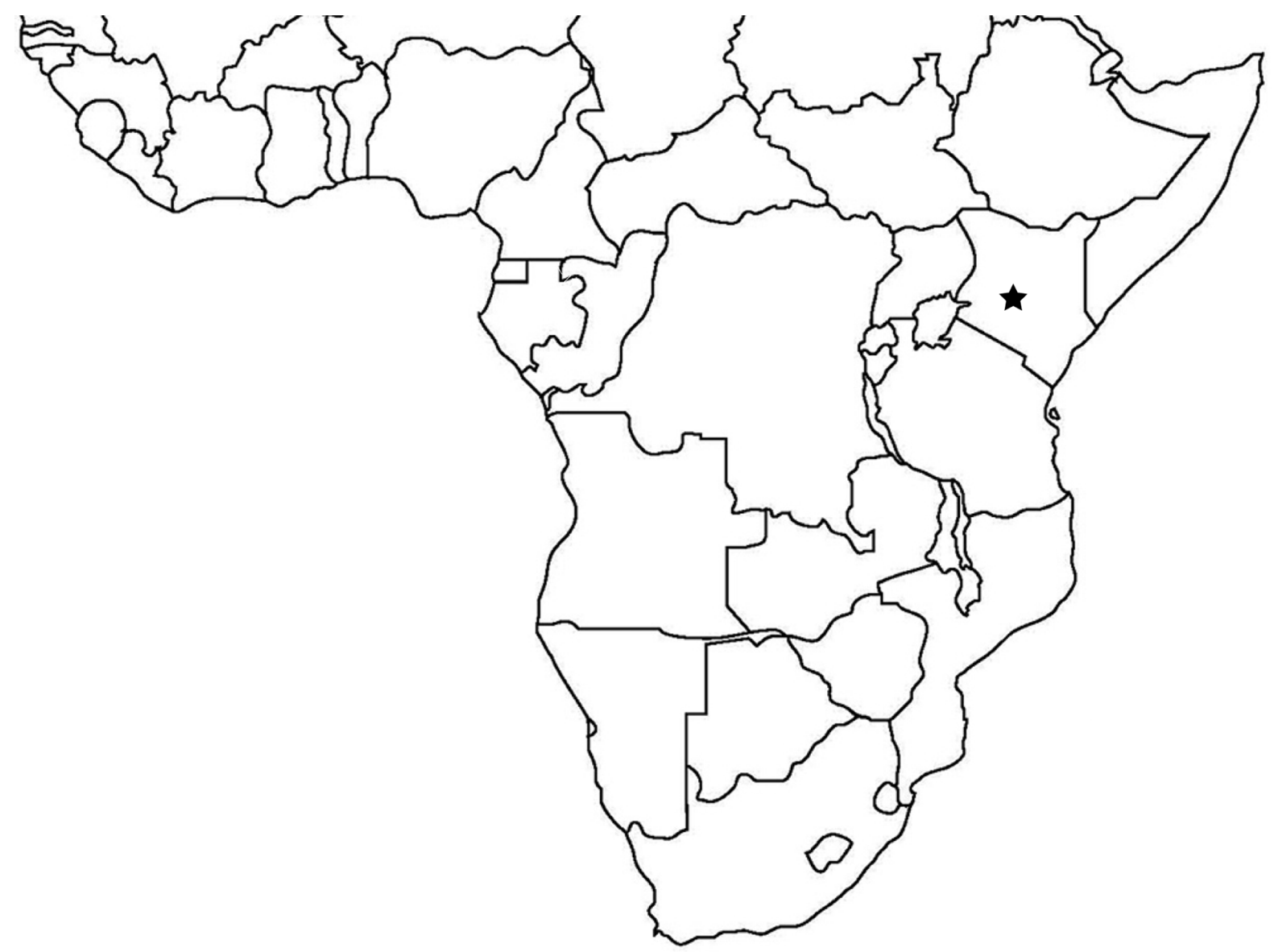

Fig. 12. Map of sub-Saharan Africa showing the type locality of Tetramorium mpala sp. nov. 
since T. mpala sp. nov. has the largest eyes (OI 31) encountered in the species complex, which contrast with the generally much smaller eyes of the other species (usually OI 16-26, only a few specimens of $T$. humbloti and all of T. tanaense have OI 27-29).

Another aspect that deserves attention here is the shape of the petiolar node in T. mpala. It is clearly squamiform like in all species of the $T$. weitzeckeri complex, but also similar to the high cuneiform and slightly triangular form found in some species of the Afrotropical $T$. squaminode species group (Bolton 1980) or the Malagasy T. marginatum and T. bonibony species groups (Hita Garcia \& Fisher 2012a). As already noted by Bolton (1980) and later by Hita Garcia et al. (2010), there seems to be a close relationship between the 11-segmented $T$. weitzeckeri group (especially the $T$. weitzeckeri complex) and the 12-segmented T. squaminode group, mainly on the basis of the spatulate sting appendage and the squamiform petiolar node. T. mpala sp. nov. appears to be an additional argument for a close relationship between these groups since its petiolar node shape is intermediate. However, at present, without a taxonomic revision of the $T$. squaminode group and a broader phylogenetic analysis of the genus Tetramorium as a whole, we prefer to keep these groups separate.

Unfortunately, the new species is at present known only from the holotype. In general, it is not recommendable to describe new species on the basis of just one specimen, since it is not unlikely that species based on singletons could just be variant forms of already known and valid species. Nevertheless, in the case of T. mpala sp. nov. we are very confident that this is not the case. The character combination of T. mpala sp. nov. outlined above is very unique, and there is no obvious morphological connection to another species of the T. weitzeckeri species complex or the entire T. weitzeckeri species group. In fact, there is no evidence at all that T. mpala sp. nov. could be a variation of another species from the $T$. weitzeckeri complex. Furthermore, T. mpala sp. nov. co-occurs at Mpala with other members of the $T$. weitzeckeri species group (T. edouardi Forel, 1894, T. zonacaciae (Weber, 1943) and T. weitzeckeri), but is easily separable from these. Consequently, we prefer to describe the new species and make it available for ant research. Hopefully, further ant sampling at Mpala Research Centre will provide more material of this interesting species.

\section{Acknowledgements}

First, we would like to thank Michele Esposito (CASC) for her assistance with data-basing and image processing, as well as the rest of the CASC imaging crew involved in the photographs used in this study: April Nobile, Erin Prado, Ryan Perry and William Ericson. We also want to thank Eva Wiesel (Wuppertal, Germany) for creating some of the montage images used in this study. Furthermore, we very much appreciate the support from Dr. Brian Brown, Giar-Ann Kung, and Weiping Xie for welcoming us to the LACM collection. Finally, we are indebted to Peter Hawkes (Afribugs, Pretoria, South Africa) and a few more anonymous users of the identification key published in Hita Garcia et al. (2010) for comments and suggestions on the key in general and certain key couplets in particular.

\section{References}

Arnold G. 1926. A monograph of the Formicidae of South Africa. Appendix. Annals of the South African Museum 23: 191-295. http://www.biodiversitylibrary.org/item/133968\#page/219/mode/1up

Bernard F. 1953. La reserve naturelle intégrale du Mt. Nimba. XI. Hymenoptères Formicidae. Memoires de l'Institut Francais d'Afrique Noire 19: 165-270.

Bharti H. \& Kumar R. 2012. Taxonomic studies on genus Tetramorium Mayr (Hymenoptera, Formicidae) with report of two new species and three new records including a tramp species from India with a revised key. Zookeys 207: 11-35. http://dx.doi.org/10.3897/zookeys.207.3040 
HITA GARCIA F. \& FISCHER G., Taxonomy of the Afrotropical Tetramorium weitzeckeri complex

Bolton B. 1976. The ant tribe Tetramoriini (Hymenoptera: Formicidae). Constituent genera, review of smaller genera and revision of Triglyphothrix Forel. Bulletin of the British Museum (Natural History), Entomology 34: 281-379. http://www.biodiversitylibrary.org/item/127476\#page/371/mode/1 up

Bolton B. 1977. The ant tribe Tetramoriini (Hymenoptera: Formicidae). The genus Tetramorium Mayr in the Oriental and Indo-Australian regions, and in Australia. Bulletin of the British Museum (Natural History), Entomology 36: 67-151. http://www.biodiversitylibrary.org/item/19533\#page/83/mode/1up

Bolton B. 1979. The ant tribe Tetramoriini (Hymenoptera: Formicidae). The genus Tetramorium Mayr in the Malagasy region and in the New World. Bulletin of the British Museum (Natural History), Entomology 38: 129-181. http://www.biodiversitylibrary.org/item/19491\#page/153/mode/1up

Bolton B. 1980. The ant tribe Tetramoriini (Hymenoptera: Formicidae). The genus Tetramorium Mayr in the Ethiopian zoogeographical region. Bulletin of the British Museum (Natural History), Entomology 40: 193-384. http://www.biodiversitylibrary.org/item/19578\#page/215/mode/1up

Bolton B. 1985. The ant genus Triglyphothrix Forel a synonym of Tetramorium Mayr. (Hymenoptera: Formicidae). Journal of Natural History 19: 243-248. http://dx.doi.org/10.1080/00222938500770191

Bolton B. 2013. AntCat: An online catalog of the ants of the world [online], version 1 Jan. 2013. Available from http://antcat.org [accessed 12 December 2013]

Brown W.L. 1957. Is the ant genus Tetramorium native in North America? Breviora 72: 1-8. http:// www.biodiversitylibrary.org/page/3190563\#page/75/mode/1up

Csösz S., Radchenko A. \& Schulz A. 2007. Taxonomic revision of the Palaearctic Tetramorium chefketi species complex (Hymenoptera: Formicidae). Zootaxa 1405: 1-38.

Csösz S. \& Schulz A. 2010. A taxonomic review of the Palaearctic Tetramorium ferox species-complex (Hymenoptera, Formicidae). Zootaxa 2401: 1-29.

Emery C. 1895. Voyage de M.E. Simon dans l'Afrique australe (janvier-avril 1893). 3e mémoire. Formicides. Annales de la Société Entomologique de France 64: 15-56. http://www.biodiversitylibrary. org/item/34283\#page/21/mode/1up

Evenhuis N.L. 2013. The insect and spider collections of the world website [online]. Available from http://hbs.bishopmuseum.org/codens [accessed 12 December 2013]

Forel A. 1891. Histoire naturelle des Hyménoptères. Deuxième partie: Les Formicides. In: Grandidier A. (ed.) Histoire Physique, Naturelle, et Politique de Madagascar: 1-280. L'Imprimerie Nationale, Paris.

Forel A. 1907. Ameisen von Madagaskar, den Comoren und Ostafrika. Wissenschaftliche Ergebnisse, Reise in Ostafrika 2: 75-92. http://www.biodiversitylibrary.org/item/131295\#page/131/mode/1up

Forel A. 1910. Ameisen aus der Kolonie Erythräa. Gesammelt von Prof. Dr. K. Escherich (nebst einigen in West-Abessinien von Herrn A. Ilg gesammelten Ameisen). Zoologische Jahrbücher, Abteilung für Systematik, Geographie und Biologie der Tiere 29: 243-274. http://www.biodiversitylibrary.org/ item/87994\#page/261/mode/1up

Forel A. 1913. Fourmis de Rhodesia, etc. récoltées par M.G. Arnold, le Dr. H. Brauns et K. Fikendey. Annales de la Société Entomologique de Belgique 57: 108-147. http://www.biodiversitylibrary.org/ item/47475\#page/128/mode/1up

Hita Garcia F., Fischer G., Peters M.K. \& Wägele J.W. 2009. A preliminary checklist of the ants (Hymenoptera: Formicidae) of Kakamega Forest (Kenya). Journal of East African Natural History 98: 147-165. http://dx.doi.org/10.2982/028.098.0201

Hita Garcia F., Fischer G. \& Peters M.K. 2010. Taxonomy of the Tetramorium weitzeckeri species group (Hymenoptera: Formicidae) in the Afrotropical zoogeographical region. Zootaxa 2704: 1-90. 
Hita Garcia F. \& Fisher B.L. 2011. The ant genus Tetramorium Mayr (Hymenoptera: Formicidae) in the Malagasy region - introduction, definition of species groups, and revision of the T. bicarinatum, $T$. obesum, T. sericeiventre and T. tosii species groups. Zootaxa 3039: 1-72.

Hita Garcia F. \& Fisher B.L. 2012a. The ant genus Tetramorium Mayr (Hymenoptera: Formicidae) in the Malagasy region - taxonomy of the T. bessonii, T. bonibony, T. dysalum, T. marginatum, T. tsingy, and T. weitzeckeri species groups. Zootaxa 3365: 1-123.

Hita Garcia F. \& Fisher B.L. 2012b. The ant genus Tetramorium Mayr (Hymenoptera: Formicidae) in the Malagasy region - taxonomic revision of the T. kelleri and T. tortuosum species groups. Zootaxa 3592: 1-85.

Hita Garcia F. \& Fisher B.L. 2013. The Tetramorium tortuosum species group (Hymenoptera, Formicidae, Myrmicinae) revisited - taxonomic revision of the Afrotropical T. capillosum species complex. Zookeys 299: 77-99. http://dx.doi.org/10.3897/zookeys.299.5063

Santschi F. 1932. Formicides sud-africains. Société Entomologique de France, Livre du Centenaire 1932: 381-392.

Sharaf M., Aldawood S.A. \& Taylor B. 2012. A new ant species of the genus Tetramorium Mayr, 1855 (Hymenoptera: Formicidae) from Saudi Arabia, with a revised key to the Arabian species. PLoS ONE 7: e0030811. http://dx.doi.org/10.1371/journal.pone.0030811

Vásquez-Bolaños M. 2007. Una especie nueva del género Tetramorium Mayr (Hymenoptera: Formicidae) de Mascota, Jalisco, México. Dugesiana 14: 93-97.

Vásquez-Bolaños M., Castaño-Meneses G. \& Guzmán-Mendoza R. 2011. New species of Tetramorium Mayr (Hymenoptera: Formicidae) from Puebla State, Mexico. Neotropical Entomology 40: 452-455. http://dx.doi.org/10.1590/S1519-566X2011000400007

Weber N.A. 1943. The ants of the Imatong Mountains, Anglo-Egyptian Sudan. Bulletin of the Museum of Comparative Zoology 93: 263-389. http://www.biodiversitylibrary.org/page/3426804\#page/289/ mode/1up

Wilson E.O. 1955. Amonographic revision of the ant genus Lasius. Bulletin of the Museum of Comparative Zoology 113: 1-201. http://www.biodiversitylibrary.org/page/2781389\#page/11/mode/lup

Manuscript received: 16 December 2013

Manuscript accepted: 10 June 2014

Published on: 15 July 2014

Topic editor: Koen Martens

Desk editor: Danny Eibye-Jacobsen

Printed versions of all papers are also deposited in the libraries of the institutes that are members of the EJT consortium: Muséum National d'Histoire Naturelle, Paris, France; Botanic Garden Meise, Belgium; Royal Museum for Central Africa, Tervuren, Belgium; Natural History Museum, London, United Kingdom; Royal Belgian Institute of Natural Sciences, Brussels, Belgium; Natural History Museum of Denmark, Copenhagen, Denmark. 